\title{
Facial Injury Severity Scale Score as a Predictor of Length of Stay for Maxillofacial Fracture at Sanglah General Hospital, Denpasar, Bali, Indonesia
}

Esther Felicita Tambayong, Nengah Kuning Atmadjaya, Nyoman Golden, Ketut Wiargitha, Tjokorda Gede Bagus Mahadewa*, Ketut Sudiasa

Departement of General Surgery, Udayana University/Sanglah General Hospital, Denpasar, Bali, Indonesia

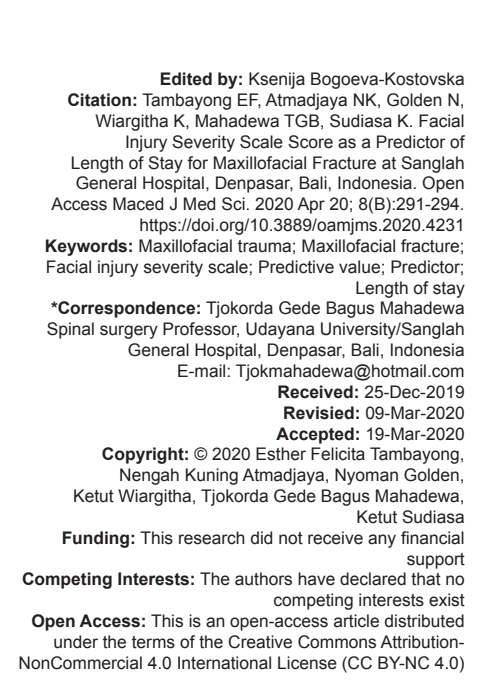

\begin{abstract}
INTRODUCTION: Maxillofacial fracture is the most common trauma that happened in the developing countries. One of the methods to evaluate the severity of maxillofacial fracture is by using the Facial Injury Severity Scale (FISS) score. Maxillofacial trauma causes multiple injuries, thus resulted in various periods of hospitalization.

AIM: The aim of this study is to use the employment of the FISS score to predict a patient's length of stay.

METHODS: This research was a retrospective cohort and cross-sectional study on maxillofacial fracture patients whom treated in Sanglah General Hospital, Denpasar, Bali. As much as 89 subjects were included in this study and information about their age, gender, mechanism of injury, FISS score, treatments, and length of stay was collected. The data were statistically analyzed using bivariate, receiver operating characteristics (ROC), and linear regression analysis.

RESULTS: A total of 89 subjects were included in this study. Among them, 50 subjects had a high FISS score, and 39 subjects had low FISS score. The average age was $28.9 \pm 13.3$ years with a mean length of stay $6.39 \pm 4.29$ days Bivariate analysis showed that the patients with high FISS score have 5.3 times higher risk to get a longer length of stay compared to those with low FISS score (95\% Cl: 2.289-12.289; $p=0.001)$. The mean of length of stay in subjects with a high FISS score was significantly higher compared to subjects with a low FISS score (mean for subjects with high score: $8.46 \pm 4.63$; mean for subjects with low score: $3.74 \pm 1.46 ; p=0.001$ ) with a correlation value $r=0.718(p=0.001)$. ROC analysis represented that FISS score $<4$ was categorized as mild. The linear regression analysis showed that the length of stay for maxillofacial fracture patients was able to be predicted by LOS $=1.476+1.032 \times$ FISS score
\end{abstract}

CONCLUSION: The FISS score can predict the length of stay for patients with maxillofacial fracture.

\section{Introduction}

Maxillofacial trauma is one of the most common traumas that found in the emergency department. The maxillofacial area is one of the most unprotected parts of the body; thus, trauma to the area increases the morbidity and mortality of the patients. In developing countries such as Indonesia, the incidents of maxillofacial trauma keep increasing as the number of traffic accidents also rising. Approximately, the incidence of traffic accident was $17.3 / 1000$ per year worldwide. The overall traffic accident mortality rate was 26.6/1,00,000 person years, which was almost 3 times higher in men than that for women [1]. In Oporto Hospital Center, Portugal, between August 2001 and December 2007, it was found the same circumstance that men had a higher incidence of maxillofacial fractures as $86.6 \%$ and road traffic accidents were the primary cause of injuries (69.38\%) [2]. About 1.35 million people died in the world due to traffic accidents [3]. In Sanglah General Hospital, Denpasar, Bali, mandible fracture was the most prone maxillofacial fracture to be found from January 2012 to November 2018, thus happening in $60.12 \%$ of total cases, followed by zygoma fracture $(30.22 \%)$ and maxillary fracture $(9.66 \%)$ [4]. About $81 \%$ of the maxillofacial trauma patients are men on their productive age, 20-29 years of age. On their productive age, people tend to have more activity to drive, work outdoor, and more social activities such as drinking alcohol and gathering with friends [2]. Wearing protection, such as helmet and seat belt, reduces the incidence of a vehicle accident. However, disobedience to those traffic regulations is still found in accordance with their education level.

The maxillofacial fracture can occur in only one part of the face, but often occurs complicated, which is also accompanied by severe trauma in other parts of the body such as head injury, spinal injury, and extremity fractures that require a long hospitalization [5]

Among all the maxillofacial fracture scores that have been found, the Facial Injury Severity Scale (FISS) score, introduced by Bagheri in 2006, 
is the most applicable and overcomes important components, namely, the mandible, maxilla, nasorbital, zigomaticomaxillofacial complex, dentoalveolar, and laceration more than $10 \mathrm{~cm}$ in length [6], [7]. The purpose of those maxillofacial scores being found is to assess the severity of the fracture quickly and precisely, increasing accuracy in diagnosing maxillofacial fractures, prognosis, and estimating the length of stay. The more severe the severity of the maxillofacial fracture, the longer the hospital stay needed.

Maxillofacial trauma often requires long hospitalization, which causes a burden to the patients and the government. In terms of health, long hospitalization is the major cause of nosocomial infections, which, in turn, will result in much longer hospitalization. In terms of finance, long hospitalization becomes an economic burden for the individual also for the countries on a large scale [8]. The aim of this study is to determine the pertinence of Facial Injury Severity Score in predicting the length of stay for maxillofacial trauma patients in Sanglah General Hospital, Denpasar, Bali.

\section{Materials and Methods}

This research was an observational analytic study using a retrospective cohort design to determine the relative risk and a cross-sectional design to determine the correlation between FISS score and length of stay at Sanglah General Hospital, Denpasar, between December 2018 and May 2019. The subjects were selected by consecutive sampling method and should meet the inclusion and exclusion criteria. The inclusion criteria were patients diagnosed with maxillofacial fractures by a physician, confirmed radiologically, and agreed to participate. The exclusion criteria were patients who deny surgery, refused to get hospitalized, accompanied by other trauma, such as severe head injury and blunt abdominal trauma, and those who were deceased.

The maxillofacial trauma suffered by the included subjects that were rated with FISS score and records on their clinical appearance and computed tomography scan result on initial admission were collected. All data were statistically analyzed using SPSS version 23.0. Significance was assumed if $p<0.05$.

\section{Results}

A total of 157 patients diagnosed with maxillofacial trauma were admitted to the Emergency Unit of Sanglah General Hospital between December
Table 1: Distribution of patients according to sex, age, cause of trauma, and treatments

\begin{tabular}{ll}
\hline Variable & Frequency (\%) \\
\hline Sex & \\
Male & $80(89.9)$ \\
Female & $9(10.1)$ \\
Age & $15(16.9)$ \\
$1-18$ & $45(50.6)$ \\
$19-30$ & $15(16.9)$ \\
$31-40$ & $7(7.9)$ \\
$41-50$ & $7(7.9)$ \\
$>50$ & $79(88.8)$ \\
Cause of Trauma & $10(11.2)$ \\
Motorbike & \\
Other & $21(23.6)$ \\
Treatment & $68(76.4)$ \\
Conservative & $4.76 \pm 2.99$ \\
Surgery & $6.39 \pm 4.29$ \\
The mean of FISS score & \\
The mean of length of stay (day) &
\end{tabular}

2018 and May 2019. As much as 68 patients were excluded because 13 patients had severe head injuries and/or blunt abdominal trauma, 34 patients refused to get surgery due to financial problems, and 21 patients deceased. Among the 89 subjects included, 80 subjects were man $(89.9 \%)$ and $9(10.1 \%)$ were woman. The mean age was $28.9 \pm 13.3$. As much as 39 subjects $(43.8 \%)$ had low FISS score $(\leq 3)$, and 50 subjects $(56.2 \%)$ had a high FISS score $(>3)$. It was found that 50 subjects $(56.2 \%)$ have a short length of stay $(\leq 5)$, and 39 subjects $(43.8 \%)$ have a long length of stay.

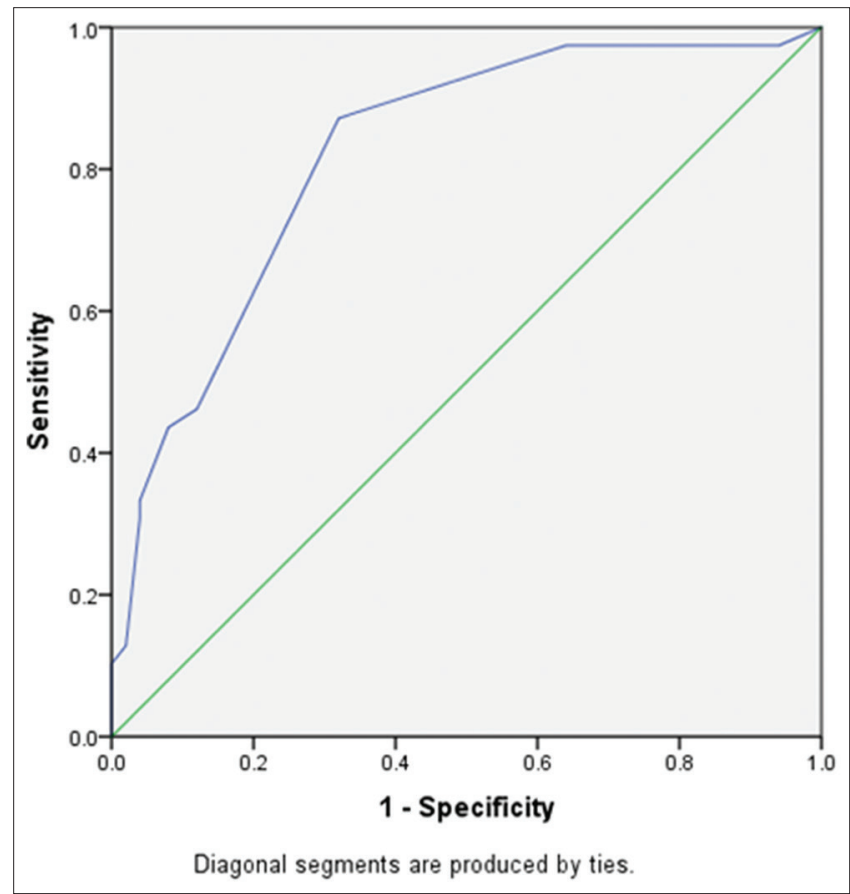

Figure 1: Receiver operating characteristics facial injury severity scale score of maxillofacial fracture patients at Sanglah General Hospital, Denpasar, Bali

The result of the bivariate analysis showed that patients with high FISS score have 5.3 times higher risk to receive a longer length of stay compared to those with low FISS score (95\% Cl: 2.289-12.289; $p=0.001)$. The mean length of stay of subjects with high FISS score $(8.46 \pm 4.63)$ was significantly higher compared to subjects with low FISS score (3.74 \pm 1.46$)$ 
$(p=0.001)$ and correlation value $r=0.718(p=0.001)$

Receiver operating characteristics analysis showed that FISS score < 4 was categorized as mild. Furthermore, the linear regression analysis showed that the length of stay of maxillofacial fracture patients could be predicted by this formula: $\operatorname{LOS}=1.476+1.032 \times$ FISS score. The accuracy rate was $52 \%$.

\section{Discussion}

In this study, it was found that the FISS score serves as a good predictor for the length of stay for maxillofacial trauma patients. FISS scores correlated significantly $(r=0.718)$ with length of stay. This finding is not in accordance with the study by Bagheri et al., in 2006. It might be due to the exclusion criteria in this study, which excluding multitrauma patients that certainly require a longer hospitalization period. However, the results of this research are in line with the previous studies conducted in Manado and Jakarta [9], [10].

Patients with high FISS score had a 5.3 times greater risk to receive longer hospitalization (more than 5 days) compared to patients with low FISS score. From the FISS score data obtained, the length of stay can be estimated using the formula LOS $=1.476+1.032 \times$ FISS score that has an accuracy level of $52 \%$. Nonetheless, there are comorbid factors that might affect the length of stay that needs further study, for instance, diabetes, hypertension, and heart disease. The cutoff point value of the FISS score used in this study was 4 . This is in adherence to the previous research conducted in Manado by Rampisela et al., 2017.

Facial trauma is a difficult case and often resulted in functional disability and facial defects. Nonetheless, the injury from such trauma to the maxillofacial area, including the upper airway tract, orodigestive tract, and the other vital organs, needs to be addressed properly. Most studies were comparing maxillofacial trauma scores with the other injury scoring systems to evaluate the length of stay, treatment costs, medical resources consumption, surgery costs and duration, number of plates needed, implant costs, sensory neural deficits, level of pain during follow-up, and post-operative complications [11], [12], [13], [14]. There are also several studies comparing the injury scores in relation to the economic burden of the patients [6].

The FISS score was chosen to determine the severity of the maxillofacial fracture in this study because this score is easy to be applied by almost all medical workers and allows for thorough maxillofacial examination [15]. However, the drawback of this score is that it does not include functional points in its assessment. The previous studies by Bagheri, Ayu Diah Kesuma - Kristaninta Bangun, the FISS score has a role in determining the length of stay [10].
The costs of treatments and hospitalization are a direct source of economic burden for the patients; moreover, the patients would be unproductive for a significant amount of time. As the FISS score system allows the physician to predict the length of stay for the patients, it may prepare the patients to allocate their expenses and to meet the requirements necessary to receive financial assistance. In addition, the patients must be informed about the importance and benefits of government health insurance.

\section{Conclusion}

This study found that the FISS score serves as a good predictor of length of stay for maxillofacial trauma patients. The higher the FISS score obtained, the longer the length of stay required. It can be counted with formula: LOS $=1.476+1.032 \times$ FISS score. It is estimated that maxillofacial trauma patients with FISS score $>3$ have a longer length of stay 5.3 times higher compared to patients with FISS score $\leq 3$.

\section{References}

1. Sehat M, Naieni KH, Asadi-Lari M, Foroushani AR, MalekAfzali $\mathrm{H}$. Socioeconomic status and incidence of traffic accidents in metropolitan tehran: A population-based study. Int J Prev Med. 2012;3(3):181-90.

PMid:22448311

2. Alves LS, Aragão I, Sousa MJ, Gomes E. Pattern of maxillofacial fractures in severe multiple trauma patients: A 7-year prospective study. Braz Dent J. 2014;25(6):561-4. https://doi. org/10.1590/0103-6440201302395

PMid:25590206

3. Brunette GW, Kozarsky PE, Magill AJ, Shlim DR. CDC health informat brunetteion for international travel 2010. In: CDC Health Information for International Travel 2010. Missouri, United States: Mosby Ltd.; 2009. https://doi.org/10.1086/649881

4. Wiargitha I, Wiradana A. Patterns of fracture site and management of maxillofacial trauma cases in the department of trauma and acute care surgery in sanglah general hospital. JBN. 2019;3(2):50. https://doi.org/10.24843/jbn.2019.v03.i02.p05

5. Adamo AAK, Editor C, Geibel J. Initial Evaluation and Management of Maxillofacial Injuries. Medscape Reference: Drug, Disease, \& Procedues. 2012.https://emedicine. medscape.com/article/434875-overview\#a1

6. Ramalingam S. Role of maxillofacial trauma scoring systems in determining the economic burden to maxillofacial trauma patients in India. J Int Oral Heal. 2015;7(4):38-43.

PMid:25954069

7. Sahni V. Maxillofacial trauma scoring systems. Injury. 2016;47(7):1388-92.

PMid:26971084

8. Bs S, Ramli R, Ahmed Z, Nur A, Ibrahim M, Rashdi M, et al Cost analysis of facial injury treatment in two university hospitals 
in Malaysia: A prospective study. Clinicoecon Outcomes Res. 2017;9:107-13. https://doi.org/10.2147/ceor.s119910

\section{PMid: 28223831}

9. Rampisela R, Lumintang N, Ngantung JT. Hubungan facial injury severity scale dengan lama rawat inap pasien trauma maksilofasial di RSUP Prof. Dr R.D. Kandou Manado. J BIOMEDIK. 2017;9(1):5. https://doi.org/10.35790/ jbm.9.1.2017.15382

10. Bangun K. Evaluation of facial trauma severity in cipto mangunkusumo hospital using FISS scoring system. JPR. 2012;1(2):163-5. https://doi.org/10.14228/jpr.v1i2.45

11. Zhang J, Zhang Y, El-Maaytah M, Ma L, Liu L, Zhou LD. Maxillofacial injury severity score: Proposal of a new scoring system. Int J Oral Maxillofac Surg. 2006;35(2):109-14. https:// doi.org/10.1016/j.ijom.2005.06.019

PMid:16188427

12. Joshi A, Solanki N, Bhuta M, Bava J. Case of double right coronary artery: Diagnosed on computed tomography coronary angiography. J Indian Prosthodont Soc. 2008;8(2):108-11. https://doi.org/10.4103/2321-449x.168469

13. Catapano J, Fialkov JA, Binhammer PA, McMillan C, Antonyshyn OM. A new system for severity scoring of facial fractures: Development and validation. J Craniofac Surg. 2010;21(4):1098-103. https://doi.org/10.1097/ scs.0b013e3181e1b3c1

PMid:20613579

14. Ahmad Z, Nouraei R, Holmes S. Towards a classification system for complex craniofacial fractures. $\mathrm{Br} \mathrm{J}$ Oral Maxillofac Surg. 2012;50(6):490-4.

PMid:22000633

15. Bagheri SC, Dierks EJ, Kademani D, Holmgren E, Bell RB, Hommer L, et al. Application of a facial injury severity scale in craniomaxillofacial trauma. J Oral Maxillofac Surg. 2006;64(3):408-14. https://doi.org/10.1016/j.joms.2005.11.013 PMid:16487802 